\title{
The Effectiveness of Using the Content and Language Integrated Learning Approach to Enhance Cultural Awareness of Tourist Guidance and Museum Guidance Students
}

\author{
Galina V. Varakina ${ }^{1, *}$ Elena V. Kulikova ${ }^{1, a}{ }^{1}$ Mikhail V. Yudin ${ }^{1}$ \\ ${ }^{1}$ Federal State Budgetary Educational Institution of Higher Education, Russian State University named after A.N. \\ Kosygin (Technology. Design. Art), Moscow, Russia \\ ${ }^{a}$ Email: elena@kulikova.pp.ru \\ *Corresponding author. Email: galina_varakina@mail.ru
}

\begin{abstract}
The article deals with the problem of teaching art guides using the content and language integrated learning (CLIL) method. Taking into account the specifics of the taught competencies, the mentioned above method seems to be the most effective one. The authors prove that by means of CLIL students have opportunities to not just master a foreign language at a professional level, but also form important skills of speaking and communicating in a professional environment, which is an important factor in increasing the demand for graduates in the labor market. The use of CLIL and its advantages are considered in the context of the project method and interdisciplinary communication, which is a kind of approbation of our academic hypothesis. In the article also there are some specific examples such as a purposely created textbook, field trips of excursion and combined type (Vernissage in tandem with a scientific conference), gamification (quest) as a form of individual or group activities. The main result of the study is the conclusion about the strengthening of the interdisciplinary educational process by using the content and language integrated learning method.
\end{abstract}

Keywords: metalanguage, cross-curriculum connections, educational process, art education, museum pedagogy, project method in university training, content and language integrated learning (CLIL)

\section{INTRODUCTION}

Modern education is increasingly focused on global changes taking place in a culture which is becoming more and more accessible. The result was the emergence of a new academic approach "an interdisciplinary methodology that allows to identify the interaction between various elements and phenomena of the socio-cultural space that exist here and now" [1]. The problem of integrated knowledge, interdisciplinary cooperation, and the creation of a specific "metalanguage" is one of the most pressing issues of modern science.

The main research challenge of the study is the justification of the priority of the method of subject-language integrated learning in the context of art criticism. This approach makes it possible to solve a set of tasks: to update the study of a foreign language by using professional vocabulary along with real communication; to master an additional (and possibly the main) means of communication in an international format; to increase the competitiveness of graduates; to introduce interactive elements in the classes and strengthen the student's motivation.

The issues of subject-language integrated learning are actively discussed in the international academic world today. This is largely due to the new format of the educational process itself and integration trends in culture and society. "With increasing student and teacher mobility dating from the beginning of the Erasmus programme in 1987 and the development of virtual exchanges via "new" educational technology, content and language integrated learning (CLIL) has now become a key strategy in the international high education playing field. And as such, it has become an object of both teaching and research." [2] 
To date, this issue has received not only applied justification and testing, but also fundamental conceptualization, an example of which is a major study by I. Fortanet-Gómez CLIL in Higher Education [3]. Some aspects of the issue and the pedagogical method of CLIL have also been studied by Russian scientists. In particular, the peculiarity of using this method in Russian technical universities was considered and tested by T. Sidorenko and S. Rybushkina (Tomsk Polytechnic University) [4]. A study by a group of academicians from Saint Petersburg State University named after Peter the Great is devoted to the issues of integrated education in the Humanities, clearly distinguishing the principle of teaching in a foreign language and through a foreign language [5]. There are didactic studies that offer a detailed review of the technology of CLIL classes, identifying the advantages and conditions of using this educational technology. Thus, in the article "Implementation of CLIL Technology in the Conditions of Polylingual Education" by Z. F. Usmanova, T. V. Zayats, G. Zh. Mukazhanova (Kazakhstan, Kokshetau State University named after Sh. Ualikhanov), the advantage of the CLIL method is proved by describing specific examples and using the statistical method. "One of the main advantages of this technology of subject-language integrated learning is to increase students' motivation to learn a foreign language. Language learning becomes more purposeful, as the language is used to solve specific communication problems" [6].

In the case, the priority of the CLIL method is obvious, which is due to the specifics of professional activity that should be mastered by art students-guides. Today, the activity of a guide is extremely popular. The requirements for the guide's erudition and communication skills are growing with the equal progression, as well as for his/her ability not just to speak informatively and engagingly, but with maximum coverage of a wide variety of audiences, including multilingual ones. In this kind of situation - when training a specialist in the field of museology and tour guides, as well as tourist services -we can observe the special effectiveness of subject-language integrated learning method. In the case described above, a foreign language is not an end in itself, but a tool for interdisciplinary communication, which is the main incentive for mastering it. In our study, this issue will be considered in two aspects: from the point of view of art criticism and from the point of view of foreign language study.

\section{INTERDISCIPLINARITY IN THE PROFESSIONAL TRAINING OF ART CRITICS}

The modern art critic has to meet the exacting needs, the range of professional capacities required in order to be competitive are expanding. Nowadays guided tours, pedagogy, and research work is not enough for art historians and art critics. Curatorship, guidance and project support are becoming more and more relevant.

All said above involves strengthening the significance of communication including international one. All this implies strengthening the role of communication, including of an international nature.

The training of an art critic, including a tour guide, is a complex system in which such disciplines as history, literature, cultural studies and art history are in priority, which opens up a wide perspective for organizing cultural and educational projects.

At the same time, it should be remembered that the improving knowledge of artistic departments students occurs primarily through the study of existing masterpieces of fine art and architecture. Each discipline is not only a source of certain information, but also has a powerful educational impact, forming personality.

Such subjects as history and literature for art students are the key knowledge to imaginative and thematic realizing of the world, including the modern one. Cultural studies, which studies culture in all its forms and manifestations and establishes the interaction of man and society, is a powerful resource not only for personal, but also for national development. The study of art history is a mandatory component of training a specialist in the field of theory and history of artistic creativity. Knowledge of historical forms of art, its valuesemantic content is important not only in understanding the modern artistic process, but also is an important reference point in pedagogical or research practice.

Museum and exhibition practice has always been a mandatory component of art education. An art critic, as well as an artist or sculptor, must be well-informed of not only the field of historical, cultural and artistic heritage, but also the issues of technology (materials, technologies for processing them, coloristics and features of interaction of an art object with the surrounding space). Today, in the age of high technologies and the existence of an active information environment, a lot of people believe that virtual space can successfully replace direct contact with art objects. However, a number of components of "live" communication are not possible in an exclusively digital format: technological nuances, features of personal spatial and subjective color perception, and the emotional component.

In addition, one of the new forms of professional self-realization of art historians is 
project activity, which requires strong skills to work in and with architectural, subject-spatial, cultural-historical, social environment. It is impossible to do it just in the classroom and via internet. For these purposes modeling the life situations and mastering the tools of interpersonal and intercultural communication is required. One of such models can be an exhibition space. Therefore, we consider visiting museums and exhibitions to be an integral part of the educational process.

Today, it is especially important to realize and evaluate the vast cultural heritage accumulated by humanity in a new way, from the perspective of modern life, to form an exigency in interacting with it, to develop an effective strategy for its comprehension, preservation and multiplication. The no easy task is successfully implemented within the museum pedagogy, elements of which can be used in different academic disciplines or their complexes. "Today's graduates meet completely different criteria, and a greater range of opportunities for professional self-realization is required" [7]. That is why the implementation of interdisciplinarity is of great importance for modern way of teaching.

The training of future art historians can not be focused just on the mastering of certain capacities. A vital requirement for any successful specialist is foreign language skills. This becomes especially relevant when it comes to excursion and exhibition practice. The tools for communication within the exhibition are both, awareness in cultural studies art history, psychology, and professional foreign language skills.

In the era of globalization, the problem of motivation for mastering foreign languages is becoming particularly relevant. A foreign language plays a huge role in the personal growth. Thanks to the help, a person gets free access to the spiritual wealth of different countries, the opportunity to communicate directly with representatives of other cultures.

According to the requirements of the new federal state educational standards [8], a university graduate has to be able to speak foreign language in interpersonal communication and professional activities. This is really important, both from the point of view of access to information and culture of peoples from different countries, and from the point of view of building partnership and friendly relations in an international format. A foreign language has long ceased to be an end in itself. Now it is a universal tool for international and interpersonal communication, allowing person to get and learn new information in the area of his/her specialty or in any other area of knowledge.
From the point of view of interdisciplinarity, a foreign language holds special meaning, since it, like no other academic subject, is open for the content of different other subjects among them, culture and art. Within the interdisciplinarity, students can study not only certain aspects of a foreign language, but can get and learn new information in the area of their specialty or in any other field of knowledge, which increases the effectiveness of the educational process.

Thus, the use of an interdisciplinary approach and elements of museum pedagogy contributes to a more solid assimilation of educational material and mastering the professional skills. The introduction to the method of subject-language integrated learning, in addition to interdisciplinarity, will allow students to expand the information and communication environment, thereby increasing their marketability in the labor market.

\section{PROJECT METHOD AND LANGUAGE TRAINING IN THE EDUCATIONAL PROCESS}

It is important for art students to communicate directly with art objects, evaluating their uniqueness through observation and emotional experience. The remoteness of significant cultural and art objects actualizes exhibition practice, as well as various technologies: video resources, virtual tours, and electronic databases. English is the universal language of such products; good English skills allow students to get acquainted with the world's cultural heritage. At the same time, the students learn special vocabulary for speaking about art in English. It can be considered as an additional incentive for studying. In the future, this for sure will allow graduates to communicate with foreign colleagues and take part in exhibitions, symposiums and conferences of an international level.

There are different technologies for integrating a foreign language into a subject-based learning system: from traditional teaching of academic subjects in a foreign language and including thematic texts and tasks in the didactic material of foreign language classes to the project method and the method of subject-language integrated learning (CLIL). The last two are fundamentally different from formal interaction of new content and a foreign language as students meet a new life challenge, the key to which is on the one hand, the necessary knowledge of their professional field and, on the other good enough language skills for transferring of his knowledge.

Let's focus on specific examples of this type of integration, which will demonstrate how the project method interacts with CLIL. 
Subject-language interaction can be organized as a game, or a quest. This is especially relevant if museums and other attractions are located in the city where students live and study. In this case, their visit can be organized in such a way, so aesthetic pleasure goes together with the acquisition of new special knowledge and English language practice. An example of this kind of practical tasks can be a collection of quests in English "Big museum journey" by E. V. Kulikova and N. V. Yakushkina [9], which opens a series of textbook that offer to combine racticing English and visiting interesting from the historical and cultural point of view sites in Moscow. The textbook provides a modern interactive approach to education by means of methods stimulating creative attitude to the completing the educational tasks through a quest, a search game that involves intellectual challenge.

Quest questions help museum or exhibition visitors to pay attention to important details and guide through the exhibition space. All the questions are formulated in English, and at the end you are supposed to share your impressions and information also in English. Completing the tasks of the quest will allow students to master more effectively the educational material based on interdisciplinary connections, deepen their knowledge of the history of art and the history of Moscow obtained in the classroom, and at the same time improve their English language skills. An exciting form of tasks will increase students' interest. The quests provide tasks for the development of familiarization, search and analytical skills.

The variety of museum themes of the practical tasks stimulates forming of general cultural competencies. Anyone who picks up this book will have the opportunity to make a fascinating journey to world-famous museums, as well as to less wellknown, but informative and interesting in their own way. The first quest leads the users to the Pushkin State Museum of fine arts, which is included in the State code of especially valuable objects of cultural heritage of the peoples of the Russian Federation. The collection of the State Tretyakov Gallery, which includes more than 1,300 works of Russian art of the XI-early XX centuries, covers such masterpieces of world significance as "the Trinity" by Andrey Rublev and "the Appearance of Christ to the People" by Alexander Ivanov, works of great artists V. I. Surikov, V. V. Vereshchagin, I. E. Repin, V. A. Serov and many others are represented in many ways is no less significant. The "Museum of retro cars" (Moscow transport Museum) with a unique collection of retro models of all types of urban transport can be very interesting, both in terms of studding foreign language and increasing one's erudition; LEGO Museum in Moscow (Museum of models made of LEGO blocks); the
Helikon-Opera theater mansion, which is so original and remarkable that it deserves attention in itself, to say nothing about the creative activities of the magnificent musical theater. Tasks can be competed individually or in mini groups. An example of interdisciplinarity can be the participation of students of the Moscow Polytechnic University in the creation of this book. The students completed the illustrations for the tasks. To do this, students-illustrators had to read the tasks, understand them, which is necessary for the maximum disclosure of their meaning and the formation of an artistic image of the illustration. Just a visit to the Museum cannot be considered as project. The project method involves several components: consolidation of previously received information, mastering new information; verbal and non-verbal communication, artistic and social; analysis and assessment of the situation within the task; and search of solutions. The purpose of the project lies not so much in getting new information, but in forming of the necessary skills and competencies needed for future professional activities. "The project method is aimed at bridging (...) the gap and establishing an internal conscious connection between what the student is studying and what work functions they will need in their professional activities. The project method not only sets a task like a seminar or practical work, but also models a situation that is close to a real one" [10].

Attending at the New Tretyakov Gallery the largest retrospective works by Vasily Polenov, dedicated to the 175th anniversary of the birth of the prominent Russian painter was a kind of a project. Attending exhibition by students was not only learning experiences, but also of great educational value. This is a real experience of interaction with the exhibition design. Students have not just to look at paintings. They have to notice what attracts visitors' attention, what is the best way to guide the group through the halls to reveal the personality and creativity of $\mathrm{V}$. Polenov. However, desired results require not only students' participation into exhibition, but also educator's initiative to set task that will activate perception, make them look at the exhibits not in a formal way. It will provide precedent for personal contact of students with the masterpieces of native and world art which as the result will promote their professional competences. The students were asked to try themselves in the role of tour guides and draw up an excursion route for Russian-speaking and English-speaking visitors to the exhibition.

The students were given a creative task: to write an essay "Exhibition of V. Polenov: Travel Notes". The main goal was to develop an individual route for the exposition with some comments. Thus, students had to carry out a whole range of theoretical and practical tasks: compiling a small 
biographical annotation, attribution of selected objects, their description with elements of analysis, psychological and semantic analysis of objects and the exhibition in general.

According to the terms of this assignment, students had to attend the exhibition (in group or individually), also it was essential to use visual materials of exhibition, press release, external inputs. However, the task was assessed by the following criterions: compilation of a route, justification of the selected objects, their correlation and language skills. The students were focused on shaping their perception of the exhibition and settle conception of their tour.

In a result students had their own projects of different formats: excursion, publicist, academical, digital (form of Internet post)

Visit to the Russian Art Week in Sokolniki (Moscow, November 1-6, 2019) can be an interesting example of activating students' personal initiative and setting situational challenges. Students had an opportunity to get acquainted with submitted for the competition pictures of modern artists from different countries and take part in the conference as an audience. Taking into account stylistic, thematic and political particularity of exposition and a presentation of a supervising teacher on kitsch in modern art, the tasks were to find an object among the exhibits and prove its involvement in mentioned phenomenon of modern culture. Not just describing of selected object but also looking for parallels in the history of art, which would be an undeniable argument of its kitsch nature was consider. So, students had to understand the essence of the kitsch phenomenon and to be able to recognize it. It is difficult to achieve this goal in the classroom. The students had a huge choice: representatives of more than 37 countries of the world, hundreds of sheets and canvases, as well as photocopies - in general about 12.5 thousand objects, most of which are symbols of their time and culture, concluding ethnic, social, mental and age definitions.

Additional intrigue was introduced by the final of the project - a round-table discussion of student's impressions in English.

It was of great value not just to speak about the event in foreign language but to defend one's point of view, the power of argumentation and conviction due to the controversy and ambiguity of the material chosen for the discussion.

Thus, we see that the project method in tandem with the principle of subject-language integrated learning has a number of advantages among them: the activity of students, their involvement in a specific life, social, cultural and communicative situation
The complexity of the approach has complex result: the unity of theory and practice, knowledge and skills, all numbered promote the development of and professional universal, general and professional competencies.

\section{Conclusion}

We considered the problem of teaching art critic-guides using the content and language integrated learning method. .The method makes it possible to have a good command of a foreign language at a professional level, and to form important skills of speaking, communicating in a professional sphere of activity, which is a significant factor in improving the labor market demand of the graduates. The advantages of using CLIL were considered in the context of the project method and cross-curriculum connections, which is a kind of validation of our scientific hypothesis.

The strong incentive and motivation are arranging of outside classes or implementing tasks at cultural and art objects, not only as a part of educational process, but also in the personal practice of students aimed at expanding their horizons and upgrading professional competence. All this is equally important in terms of training qualified specialists and of educating an erudite, harmoniously developed person. The absence of a classroom removes the tension that students experience in most cases, perceiving the teacher as a counter-force. "It is dialogue training that allows a student and a teacher to disclose the essential meanings of the phenomena in question. At the same time, the pedagogical influence of the teacher on the student is being replaced by personal interaction, where both become co-authors of this process". [11]

These are the requirements the State Standards of the new generation impose on graduates of higher education institutions. In turn, the educational process is not based on abstract knowledge, but on specific professional competencies listed in professional standards. In addition, the individualized approach to education and the development of flexible pathways of education are important. All this radically changes the concept of modern education, in which is based "not only on the knowledge component of the learning process, but also the individual's ability to continue education in the chosen area of knowledge" [12].

Thus, the use of the subject-language integrated learning method, together with the project method based on cross-curriculum connections, advances the student to use the acquired knowledge in a specific professional situation, forming the necessary competencies, which is the basis of his motivation in learning. 


\section{References}

[1] N. V. Sinyavina. Culture as a self-developing system and the possibilities of an interdisciplinary approach in its study // Pedagogy of art. - 2018. -3. - P. 63-68. - P. 64.

[2] G. Taillefer. CLIL in higher education: the (perfect?) crossroads of ESP and didactic reflection, p. 31-53. https://doi.org/10.4000/asp.3290.

[3] I. Fortanet-Gómez. CLIL in Higher Education. Towards a Multilingual Language Policy. Series: Bilingual Education \& Bilingualism. Multilingual Matters, 2013. DOI: https://doi.org/10.21832/9781847699374.

[4] T. Sidorenko, S. Rybushkina. Content and language integrated learning in russian technical universities. The Education and science journal. January 2017. 19(6), p. 182-196. DOI: 10.17853/1994-5639-2017-6-182-196.

[5] T. A. Baranova, A.M. Kobicheva, E. Yu. Tokareva. Effectiveness of using CLIL-training on the example of humanitarian disciplines // Modern

[6] Z. F. Usmanova, T. V. Zayats, G. Zh. Mukazhanova. Implementation of CLIL technology in the context of multilingual learning / / Philology and linguistics in the modern world: materials of the I international. scientific Conf. (Moscow, June 2017). - Moscow: Buki-Vedi, 2017. $\begin{array}{lccr}- & \text { P. } & 94-97 . & \text { URL: }\end{array}$ 01.09.2020).

[7] G. V. Varakina. Professional self-realization of a graduate of a humanitarian University in the virtual space // Modern technologies in science and education-STNO-2019 [text]: sat. Tr. II international forum: in 10 t. T. 9 . / General ed. O. V. Milovzorov. - Ryazan: IP Konyakhin A.V. (Book Jet), 2019; Ryazan. - 224 p.: - P. 202.

[8] Federal state educational standard of higher educationbachelor's degree in 50.03.04 theory and history of arts. Approved by order of the Ministry of education and science of the Russian Federation of June 15, 2017 N 557 [Electronic resource]. Access mode: http://fgosvo.ru/news/21/3421.

[9] E. V. Kulikova. N. V. Yakushkina. Big museum journey. Kazan: Buk, 2019. - 86 p.

[10] G. V. Varakina. Project method in modern Humanities education // Modern technologies in science and educationSTNO-2020 [text]: sat. Tr. III international forum in $10 \mathrm{t}$. T. 9 / General ed. of O. V. Milovzorov. - Ryazan: Ryazan State Radio Engineering University. UN-t, 2020. - 242 p. P. 219.

[11] E. V. Kulikova. Humanistic paradigm in foreign language teaching in higher education // Modern technologies in science and education-STNO-2020 [text]: sat. Tr. III international forum in 10 t. T. 9 / General ed. of O. V. Milovzorov. - Ryazan: Ryazan State Radio Engineering University. UN-t, 2020. - 242 p. - P. 214.

[12] D. V. Smirnov, I. I. Kholodtsova, M. V. Yudin. First international competition of diploma projects on children's tourism and local history "UNIVERSITY for children": results, experience of the organization, prospects // Bulletin of the Academy of children's and youth tourism and local history. - 2015. - № 4 (117). - P. 156-173. - P. 159. 